\title{
En torno al tapiz intitulado Speculum humanae vitae que fue de Doña Emilia Pardo Bazán
}

\author{
Amparo López Redondo *
}

\begin{abstract}
RESUMEN
ABSTRACT

En este artículo se presenta un tapiz

This article presents a tapestry intitled

intitulado speculum humanae vitae,

custodiado en el Museo de Bellas

Speculum humanae vitae wich belongs to the Museo de Bellas Artes from

Artes de la Coruña, indicándose que la fuente de inspiración del mismo fue

un grabado xilográfico al claro

obscuro, obra de Aridrea Andreani

(Mantua 1560-1623), inspirado en un dibujo de Fortunio hecho en Siena en

1588. Se establece la relación del mismo con la Biblia y con la literatura

del Siglo de Oro y finalmente se aventura el posible uso de éste desde

su manufactura hasta la actualidad

indicando que perteneció a Doña

Emilia Pardo Bazán.

La Coruña. Inspired by a chiaroscuro engraving by Andrea Andreani (Mantua 1560-1623) based on a drawing by Fortunio made in Siena in 1588, this article analyzes its iconography and explicative inscriptions, concluding that this piece belongs to the CounterReformation current as opposed to the category of Reformation vanitas. The relationship between the tapestry and the Bible as well as Golden Age Literature will be discussed. Finally, the functions of this piece from its production and until the present will be postulated noting that it belonged to Doña Emilia Pardo Bazán.
\end{abstract}

En el número 26 de la revista ABRENTE presenté un tapiz inédito, que lleva por lema el de Speculum Humanae Vitae (fig. 1) donado por la Condesa de Esteban Collantes el año de 1969 al Museo de Bellas Artes de La Coruña. Esto dio lugar a una exposición que se celebró en el mismo Museo, en la que se presentó el tapiz junto con un selecto grupo de obras, vanitas y reflexiones diversas sobre la muerte, que permitían la compren-

* Conservadora Facultativa. Museo Lázaro Galdiano. 


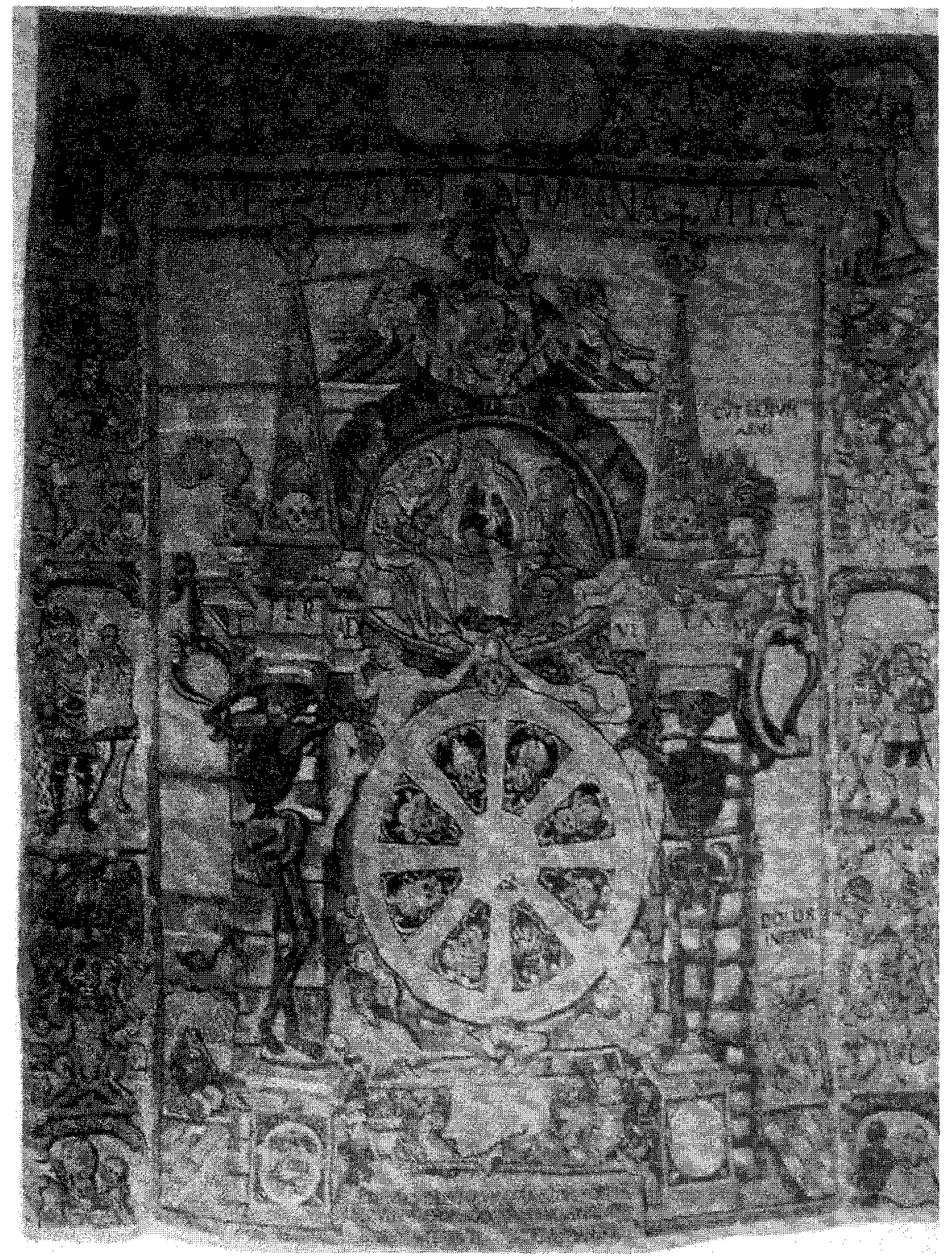

Fig. 1. Tapia «Speculum Humanae Vitae». 
sión contextualizada de la obra. En el citado artículo daba a conocer esta pieza, hacía una descripción iconográfica y añadía la trascripción y traducción de sus textos latinos. Mis investigaciones posteriores, sobre dicha obra, me han permitido descubrir y localizar la fuente en que se inspiró así como confirmar la datación aproximada que para ella proponía y algunos otros extremos que aventuraba.

En la Biblioteca Nacional de Madrid se conserva una xilografía al claroscuro realizada por el grabador italiano Andrea Andreani (Inv. 41160) que representa exactamente el motivo central del tapiz (fig. 2) y reproduce con ligeras variantes sus leyendas. Si con ello la fuente del tapiz se pone en evidencia, se confirma la fecha que sugeríamos para el mismo: lo situabamos a finales del siglo $\mathrm{XVI}{ }^{1}$, basándonos en la indumentaria de los personajes y en el estilo arquiteciónico que mostraba. El grabado de Andreani es de 1588. Con esto tenemos un termino post quem para la confección de nuestro tapiz.

El grabado representa un monumento sepulcral adosado a la pared con arco triunfal que enmarca un sarcófago abierto en el que se puede ver el perfil de un cadáver. Tal vez, se trata de la representación de un monumento funerario efímero. Vamos a señalar las analogías y diferencias entre las dos obras:

Para empezar, el inismo título del tapiz, no existe en el grabado, y es un ejemplo del uso complementario y explicativo de la literatura con respecto a la imagen. Efectivamente Speculum humanae vitae, es un inequívoco resumen de lo representado en el mismo. La traducción literal sería la de "Espejo de la vida humana" "2, pero el empleo del término Speculum aquí como en muchas otras obras literarias del momento se comprende mas con el sentido de «tratado» o «reflejo». Por ello estamos en realidad ante una reflexión sobre la vida humana cuya culminación es la muerte. Esta aclaración tiene interés porque ayuda a entender las razones profundas de una obra tan ecléctica y compleja, con un programa iconográfico novedoso e interesante que sigue la orientación contrarreformista, pero sin dejar de volver atrás la mirada y de recurrir a tópicos clásicos y medievales.

El tapiz presenta fundamentalmente el tema del «triunfo de la muerte» al que alude en primer lugar la estructura del arco triunfal, un motivo clásico tomado por el renacimiento y muy del gusto de las ceremonias del barroco. En el centro del arco se inscribe la rueda de la fortuna bajo la presencia de las Parcas, para insistir así en la naturaleza fortuita e igualatoria 


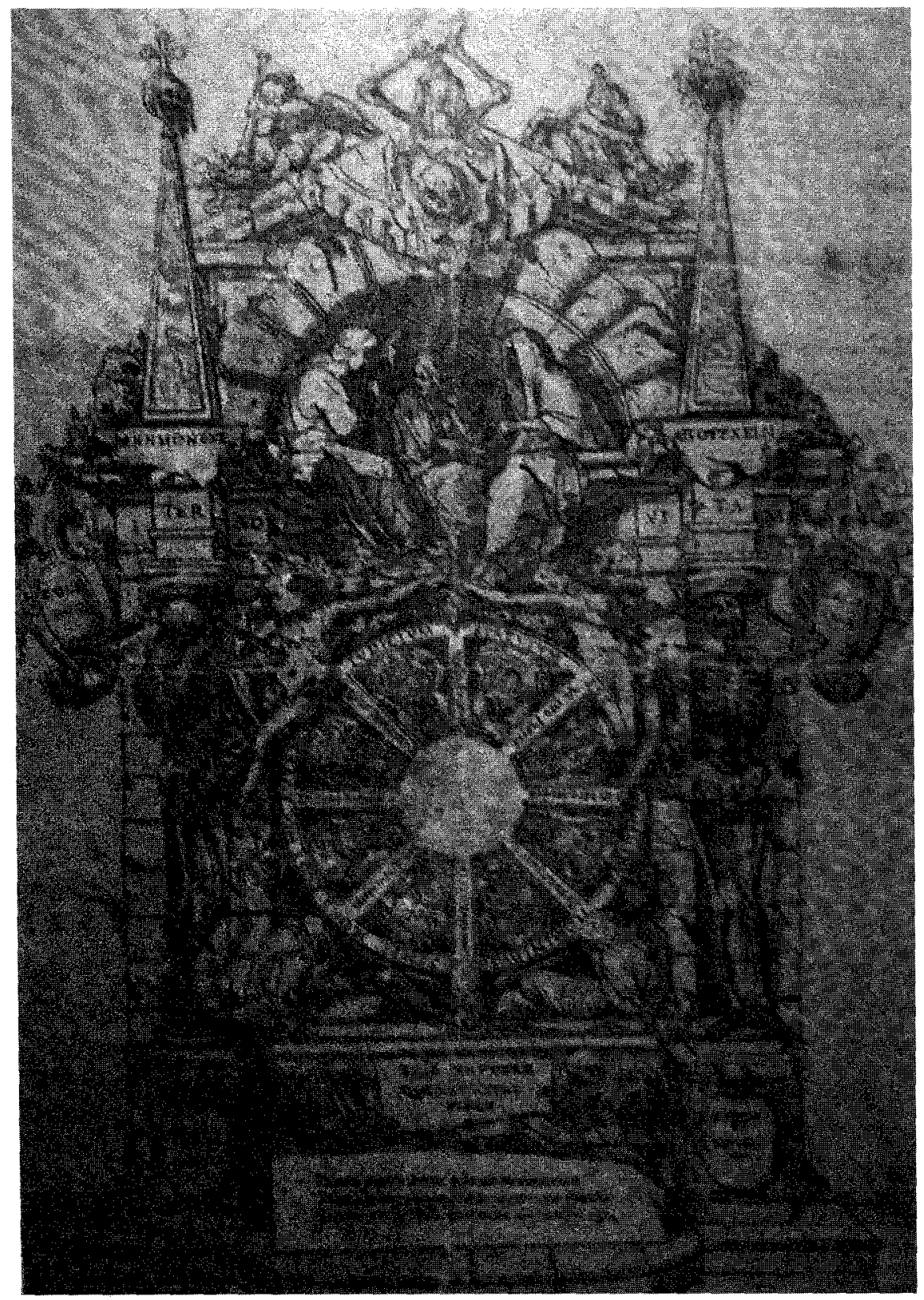

Fig. 2. Xilografía de Andrea Andreani: El Triunfo de la Muerte (Biblioteca Nacional de Madrid). 
de la muerte, aspecto éste que se desarrolla con amplitud en la cenefa externa del tapiz aunque no aparece en el grabado y que deriva de la danza de la muerte, esa iconografía que nace en el cementerio de Los Inocentes de París en 1424, cuyas representaciones más conocidas son las de Holbein, Sebald Beham o Baldung Grien, las cuales inspiraron sin duda los motivos de estas franjas. Su protagonista es, en este caso, el esqueleto, es decir, la universalización de la muerte, y no la figura del transido, en realidad el doble del vivo una vez muerto; la presencia en el tapiz del esqueleto apunta a la estética del barroco. El espíritu contrarreformista, en efecto, retoma el motivo macabro de la danza por su carácter democratizador, por su brutal manera de señalar la igualdad de todos los mortales ante la muerte. A los más desfavorecidos socialmente esta idea les sirve en cierto modo de alivio de su desdicha y a la Contrarreforma de admonición para el arrepentimiento general de los pecados.

El motivo central del grabado es también una rueda de la fortuna de iguales características a la del tapiz, en cuya circunferencia externa se encuentra la frase de la carta de San Pablo a los Hebreos $(9,27)$ Statutum est omnibus hominibus semel mori post hoc avtem ivdicivm ${ }^{3}$. Los radios tienen, como en el tapiz, leyendas latinas tomadas del libro de Job y del de Isaías que terminan todas en la sílaba mvs, que en el ejemplar de la B.N. Inv. 41160 no aparece pero si en otras tiradas de la misma obra de las que luego hablaremos. Entre los radios del grabado y del tapiz se ven unos cráneos aderezados con distintos tocados según la dignidad seglar o religiosa que representan: un papa, un emperador, un monarca, un príncipe, un obispo, un cardenal, un guerrero, y un hombre del común, éste con su cráneo desnudo. Todo ello en clara alusión a la filosofía de la Danza Macabra: la muerte a todos iguala.

En cuanto a las leyendas latinas de los radios de la rueda hay entre una y otra obra algunas diferencias.

Las del tapiz, siguiendo el sentido de las agujas del reloj, son:

CVM NOS TERRA SI(MVS)
TERRA EST QVAE SV(MVS)
MORTE VANESCI(MVS)
DE LIMO HOMO PRI(MUS)
QUID EST HOMINIS LI(MVS)?
VNDE SVPERBI SV(MVS)?
VT DEO PLACEA(MVS)
VT DEO STVDEA(MVS)

CVM NOS TERRA SI(MVS)

TERRA EST QVAE SV(MVS)

MORTE VANESCI(MVS)

DE LIMO HOMO PRI(MUS)

QUID EST HOMINIS LI(MVS)?

VNDE SVPERBI SV(MVS)?

VT DEO STVDEA(MVS)

\author{
Siendo nosotros tierra \\ Tierra es lo que somos, \\ Con la muerte desaparecemos \\ De barro fue hecho el primer hombre \\ ¿Que es el barro del hombre? \\ ¿De donde somos soberbios? \\ Agrademos a Dios \\ Tengámoslo presente.
}

3 Esta misma frase está en la contraportada del libro de Carlos Bundeto El espejo de la muerte, en el que se notan los Medios de prepararse para bien morir (..), Amberes, 1700. 
El grabado de Andreani muestra las siguientes en diferente orden:

Cvm nos terra li(mvs)
Terra est quasi fv(mvs)
Morte[m] vitare nequae(mvs)
De limo homo pri(mus)
Quod est homo nisi limvs?
Vnde svperbi sv(mvs)?
Vt deo placea(mvs),
Et ideo stvdea(mus)

Cvm nos terra li(mvs)

Terra est quasi fv(mvs)

De limo homo pri(mus)

Quod est homo nisi limvs?

Vt deo placea(mvs)

Et ideo stvdea(mus)

\author{
Siendo nosotros barro \\ La tierra es como el humo \\ No podemos evitar la muerte \\ De barro fue hecho el primer hombre \\ ¿Que es el hombre sino barro? \\ ¿De donde somos soberbios? \\ Cuidemonos de agradar a Dios, \\ $Y$ esforcémonos, por tanto.
}

Las variaciones, como puede observarse, son mínimas. La comparación permite descubrir el error del tapiz en el último verso: vt deo studeamvs en lugar de et ideo stvdeamvs.

Sobre la rueda están las figuras de Adán y Eva que recuerdan el origen del pecado y de la condición mortal de los humanos. Sostienen entre las manos una granada, que apoyan sobre una calavera: símbolo de la iglesia como camino de vida, lo que refuerza la leyenda Iter ad vitam inscrita en el friso que cierra la escena. Sobre este friso están sentadas las tres Parcas, que cobijadas por la bóveda de cuarto de esfera, hilan y sostienen el camino de la vida (fig. 3). Sobre el frontón que corona el arco pende, estampado sobre un paño,

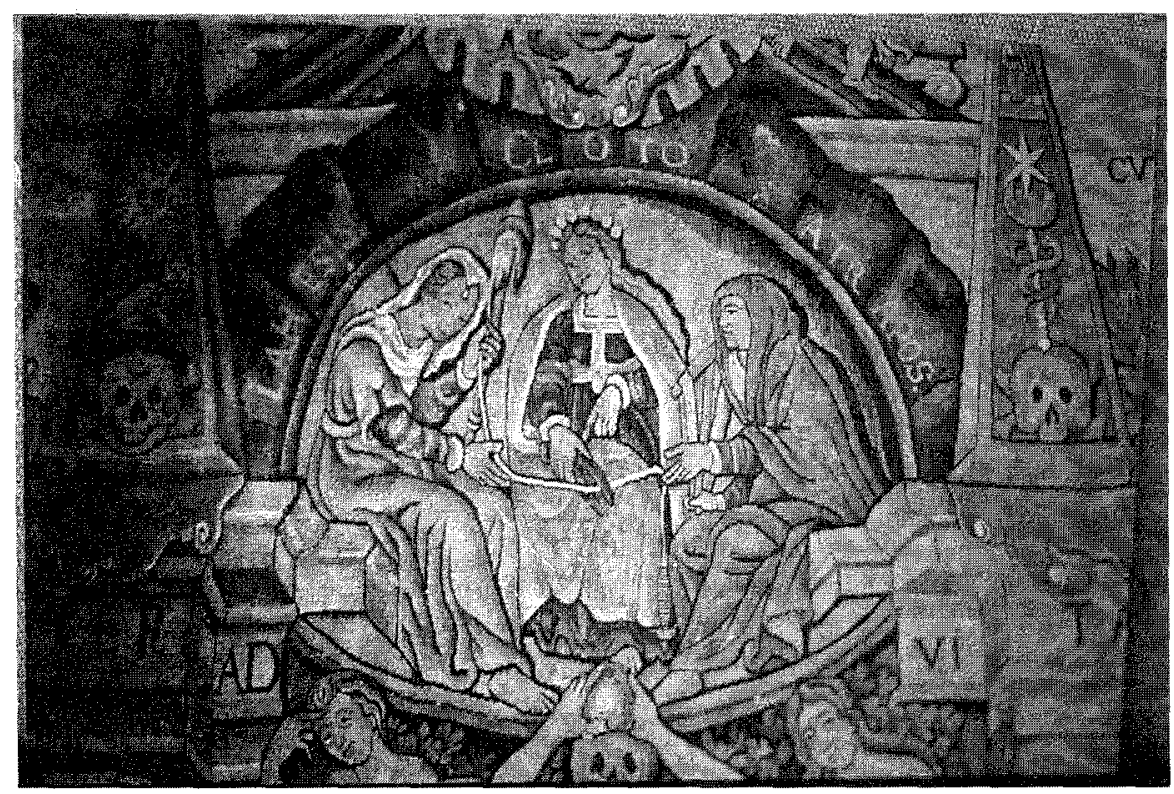

Fig. 3. Detalle del tímpano con las Parcas del Tapiz «Speculum Humanae Vitae». 


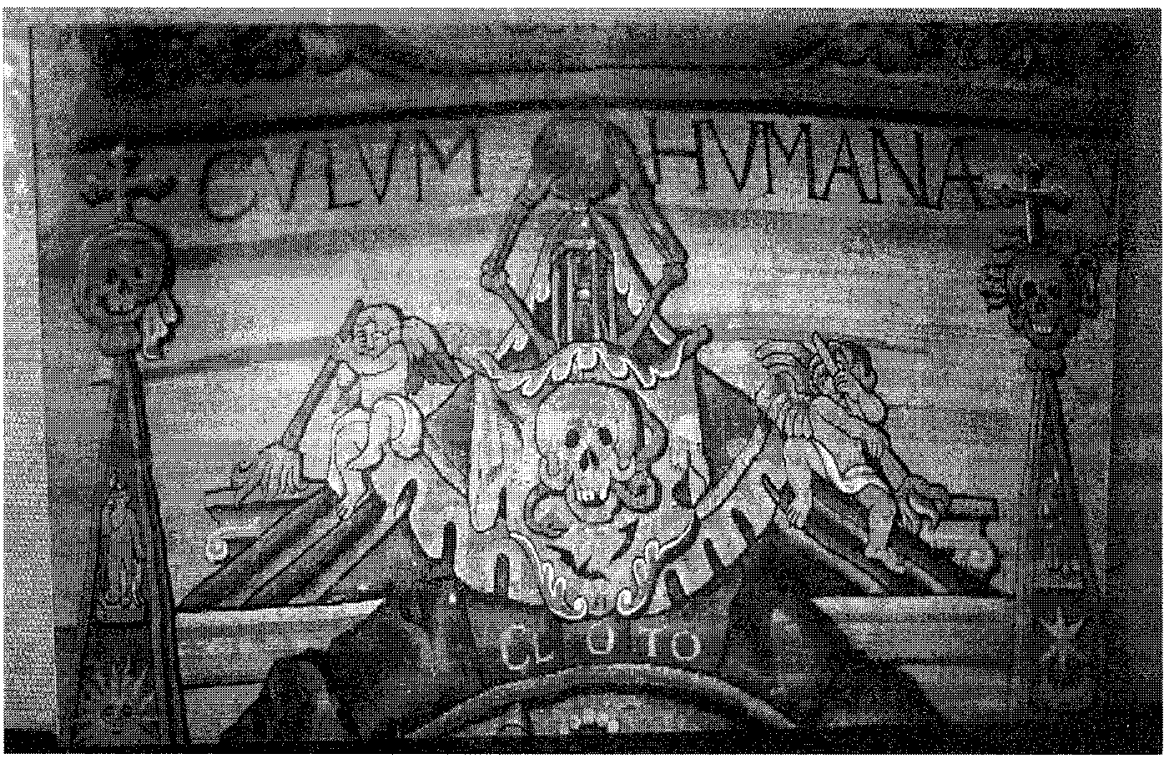

Fig. 4. Escudo del frontispicio en el tapiz «Speculum Humanae Vitale».

el escudo de la muerte. (fig. 4). Indudablemente se inspira en el «blason de la mort» de la Danza macabra de Holbein donde se le ha querido ver retratado con su esposa (fig. 5). En cambio, en el grabado son dos angelotes con las antorchas hacia abajo, (símbolo del Hades), los que sostienen el emblema.

Todo el programa iconográfico descrito se desarrolla sobre un féretro custodiado por dos personajes con el típico atavío funerario. Cubiertos totalmente con negras vestiduras, en actitud de recogimiento reflexivo, parecen aconsejados por el genio que acompaña a cada uno de ellos: un ángel y una lechuza. En el frente del féretro se encuentran agrupadas las cosas dejadas por los humanos al dejar este mundo: arreos militares, libros, tocados, cetros y coronas. Alusiones a la vanidad de las ilusiones y a la fugacidad del tiempo. Como en el tapiz, aparecen las leyendas:

\author{
tria svnt vere / quae me facivnt /flere \\ primvm quidem dvrvm quia scio me moritvrvm \\ secvndvm vero plango, \\ quia moriar, sed nescio qvando \\ Tertivm avtem flebo, \\ qvia nescio vbi manebo
}

Tres son en verdad las cosas que me hacen sufrir /primero ciertamente es duro /saber que he de morir / En segundo lugar me lamento en ver- 


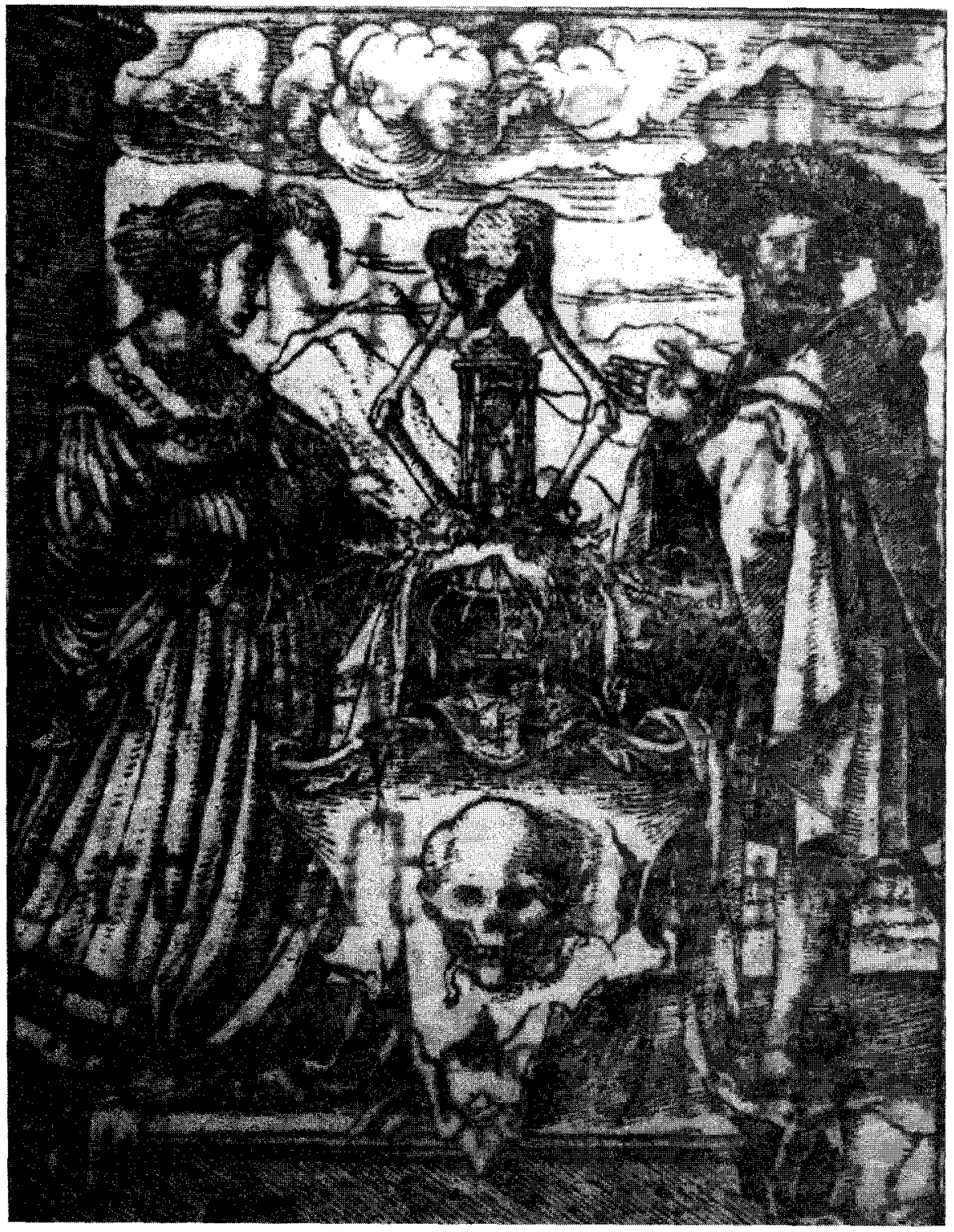

Fig. 5. La Danza macabra de Holbein, emblema del primer grabado. 
dad/ por tener que morir y no saber cuando. /Tercero ciertamente lloraré / porque ignoro donde permaneceré.

El autor del cartón del tapiz acerca al espectador el grabado de Andreani, explicando lo implícito con cierta ingenuidad. Se dota, por ejemplo, de rostros a personajes que en el grabado los tienen ocultos tras los mantos, para reforzar la escena en torno al féretro, es decir el momento en que se decide la salvación o la condena del alma, se concreta muchísimo más la figura que reflexiona ante el féretro, figura tan difuminada en el grabado, que parece una máscara. Se incluye además a cada uno de los lados de la misma la representación de la disyuntiva planteada al difunto: gloria caeli, dolor inferni. Los rasgos generales del trazado son más toscos. Nos encontramos, pues, ante la popularización de un motivo culto.

Asimismo se percibe en esta escena la influencia de un género literario que florece en la Edad Media y que está de nuevo en auge, el ars moriendi, del que es un buen ejemplo el libro de Carlos Bundeto ${ }^{4}$. En este sentido el barroco aparece una vez más como prolongación del espíritu medieval. Se basa este tipo de literatura en la doctrina del juicio post mortem ${ }^{5}$ y presentan la salvación o la condena del difunto como una disputa entre un ángel y un demonio. Con ello se comprende la significación de los personajes del tapiz y de su sentido ante el féretro.

Tenenti ${ }^{6}$ ha señalado en su estudio sobre los Ars Moriendi la irresponsabilidad del difunto que presencia, como un espectador, la disputa entre ángeles y demonios desde su lecho mortuorio. Pero en la visión contrarreformista y en la que se plantea en esta obra, el difunto parece haber tenido que elegir entre los horrores del infierno y la gloria del cielo, que están reiterados en una zona que no forma parte ya del dibujo creado por Fortunio con las inscripciones Gloria caeli , Dolor inferni y la escenificación algo ingenua de ellas.

El conjunto se encuentra flanqueado por dos grandes esqueletos en dispar actitud en correspondencia con las leyendas: mors / bonis /bona y mors/ malis / mala situada a cada uno de los lados.

Bajo los esqueletos están las leyendas latinas memento mori y memorare novisima que en el grabado se corresponden con los textos griegos bajo los pináculos.

Los esqueletos, en una y otra obra, actúan como cariatides que soportan la estructura arquitectónica, que tiene a cada lado un pináculo pirami-

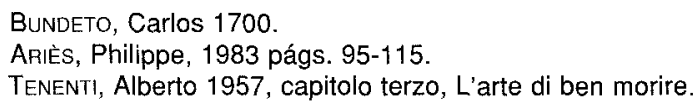


dal en forma de obelisco, cuyos motivos inscritos parecen basados en I lerogliphici de Pierio Valeriano, obra de gran evolución e influencia iconográfica en el mundo artístico de la Italia del Cinquecento.

En el ángulo inferior izquierdo del grabado hay una interesante inscripción que reza lo siguiente: III(ustrissimo) D(omino) Petro Caballo i(n) c(ivitate) Pontremu(uli) Relig(ioso) D(ivi) Steph(ani) ordinisque milit (aris) ser(enissi)mi M(agni) D(ucis) Hetr(uriae) auditori / dign(o) Joh(annes) Fortuna Fortunius Inven(it) Senis MLXXXVIII. La inscripción indica que se trata de una obra hecha para Pietro Cavallo en la ciudad de Pontremuli, quien era miembro de la Orden de San Esteban, fundada por Grammont (n. Thiers 1046, + Muret 1124), orden de una gran rigidez, seguidora de la regla de San Benito. Informa también que Pietro Cavallo era oidor en Pontremuli del Gran Duque de Toscana y que el autor del dibujo sobre el que se realizó el grabado es Joh (annes) Fortuna Fortunius que lo hizo en Siena en 1588. Pudiera creerse que este personaje fue tanto el autor del dibujo como el estampador, pero en la basa inferior derecha aparecen las dos Aes superpuestas que son el anagrama de Andrea Andreani.

Sabemos de Andreani que fue en ocasiones protegido de los Gonzaga, que trabaja a menudo sobre dibujos ajenos, a veces de pintores conocidos. Debido al mal estado de conservación del grabado que manejamos, no podemos asegurar que la inscripción rece Joh, por tanto Johannes y no Job y sea una referencia al autor bíblico. En este segundo caso parecería que ese extraño Fortuna Fortunius fuese una broma de Andreani y una referencia al motivo central del grabado (la fortuna) y a la inscripción del libro de Job que en ella se encuentra. Un juego de palabras que en realidad escondería, tras de sí, el del autor del dibujo. Sin embargo Fortunius aparece como autor de este dibujo, en todos los repertorios donde hemos encontrado alguna referencia a este grabado. Asi Bartsch ${ }^{7}$ lo incluye en su repertorio e indica la existencia de dos grabados uno con la desinencia -MVS en el centro de la rueda y otro sin ella; El Bartsch llustrado ${ }^{8}$ reproduce un nuevo ejemplar custodiado en el Museum of Art Modern de New York que tiene en el centro de la rueda un esqueleto acurrucado, armado de su habitual guadaña (fig. 6).

Por otra parte, existe en la British Library ${ }^{9}$ una entrada encabezada por Fortunius referida a una carpeta que incluye además de esta estampa, un grupo de obras relacionadas con el tema: monumentos, iconografía, ceremonias, etc. También aparece mencionado en dos repertorios muy

BARTSCH, Adam 1802-1821 pág. 135, 136 nº 13.

Bartsch the ilustrated 1978 il. $135.13 \mathrm{I}$.

Fortunius, (Johannes Fortuna) 1588 1518-1630 íl. 
En torno al tapiz intitulado Speculum humanae vitae que fue de Doña Emilia...

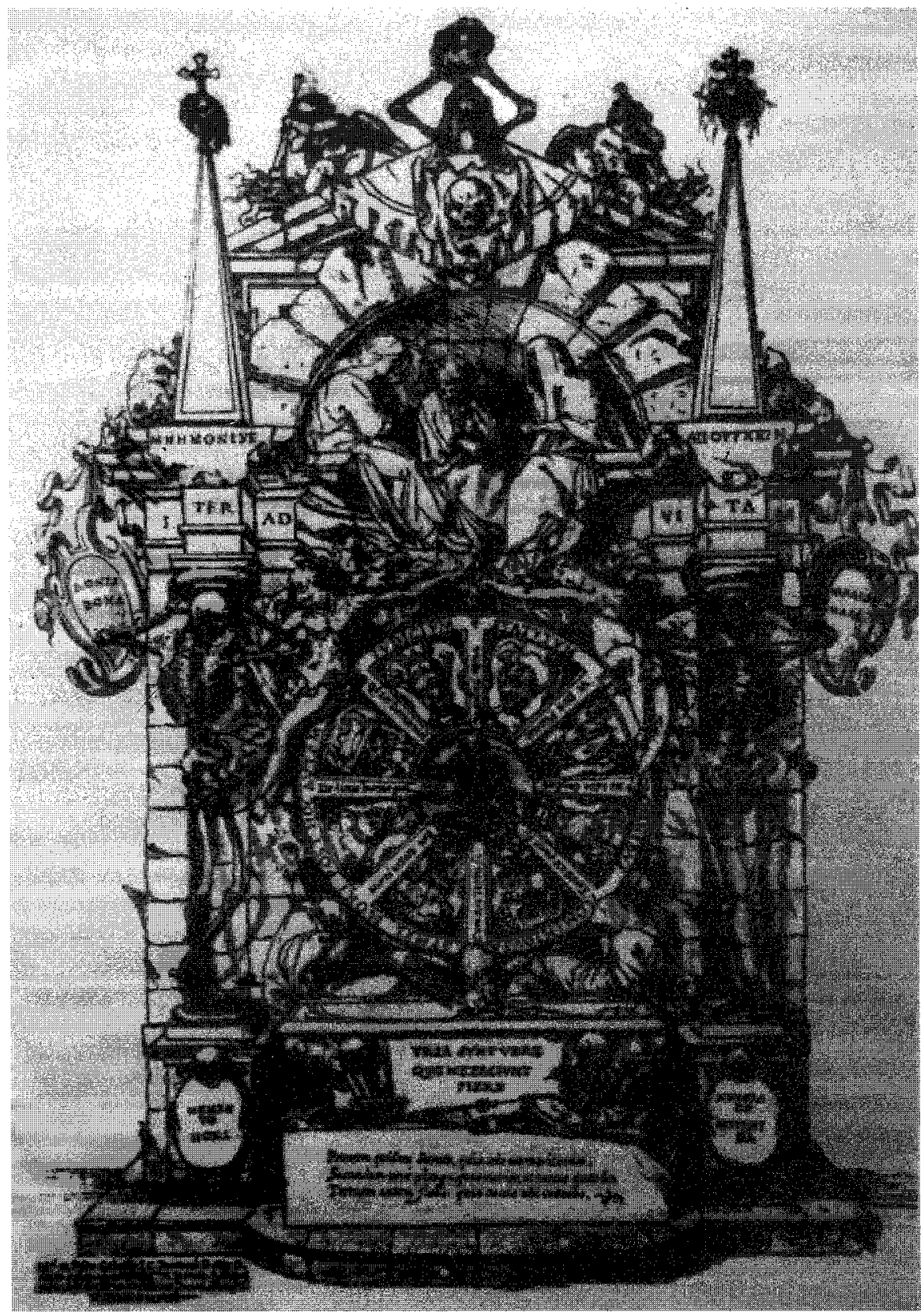

Fig. 6. Xilografía de Andreani (ejemplar de Nueva York). 
importantes del siglo pasado, el manual de Le Blanc ${ }^{10}$ y el diccionario de Bryan "1.

El grabado de Andreani es una xilografía al claroscuro de gran belleza y excelente trazado, superior al tapiz aunque represente el mismo motivo, ya que este es de menor tamaño y calidad en el dibujo y de factura popular. Entre los ejemplares conservados el de mayor interés es sin duda el del museo neoyorquino que tiene en el centro de la rueda de la fortuna la figura de un esqueleto sentado sosteniendo la guadaña que le es propia y recostando su cabeza en la mano derecha que, a su vez, descansa en la sílaba -MVS .De este singular modo se refuerza el carácter democratizador de la Parca al apoyarse en la desinencia de la primera persona del plural. También en el M.M.A. se conserva la xilografía al claroscuro realizada por el mismo grabador en 1610 y que representa el Juicio Final según dibujo de Battista Franco, II Semoleo, considerado por Vasari como uno de los mejores dibujantes de su época, una buena muestra de la mentalidad contrarreformista del momento. Esta dedica la estampa a Ludovico Gonzaga que fue durante un periodo de tiempo su mecenas.

En lo que respecta a la xilografía de Andreani que inspira el tapiz Speculum humanae vitae se ha de decir lo mismo, se trata de un claro motivo contrarreformista de raigambre medieval, en el que se incorporan novedades manieristas para representar el triunfo de la muerte,con elementos propios del barroco, un motivo, como ya hemos señalado, de amplia difusión en los paises de mayor implantación de la Contrarreforma, es decir España, Italia y Francia.

En este sentido, es interesante indicar la existencia de un grabado de Edmonde Moreau 12: L'Arc Triomphal de la Mort (fig. 7) de la segunda mitad del s. XVII, en el que están presentes los elementos fundamentales y la misma estructura de arco triunfal del grabado de Andrea Andreani, con ciertas variaciones en el motivo central que confieren un mayor patetismo a la obra. Nos encontramos, pues, ante un modelo que se repite, con ligeras variaciones, para transmitir un invariable mensaje: el carácter democrático de la muerte, y la esperanza en la resurrección por la redención de los pecados.

El mensaje es el del espíritu de la Contrarreforma cuyo propagador principal fue la Compañía de Jesús. Los ejercicios esprituales de San Ignacio,

10 Le Blanc, M. Ch.1854, págs. 42 tomo 1.

BRyans 1816 págs. 29-30.

Coste Messelière, Marie Geneviève. 1959. 
En torno al tapiz intitulado Speculum humanae vitae que fue de Doña Emilia...

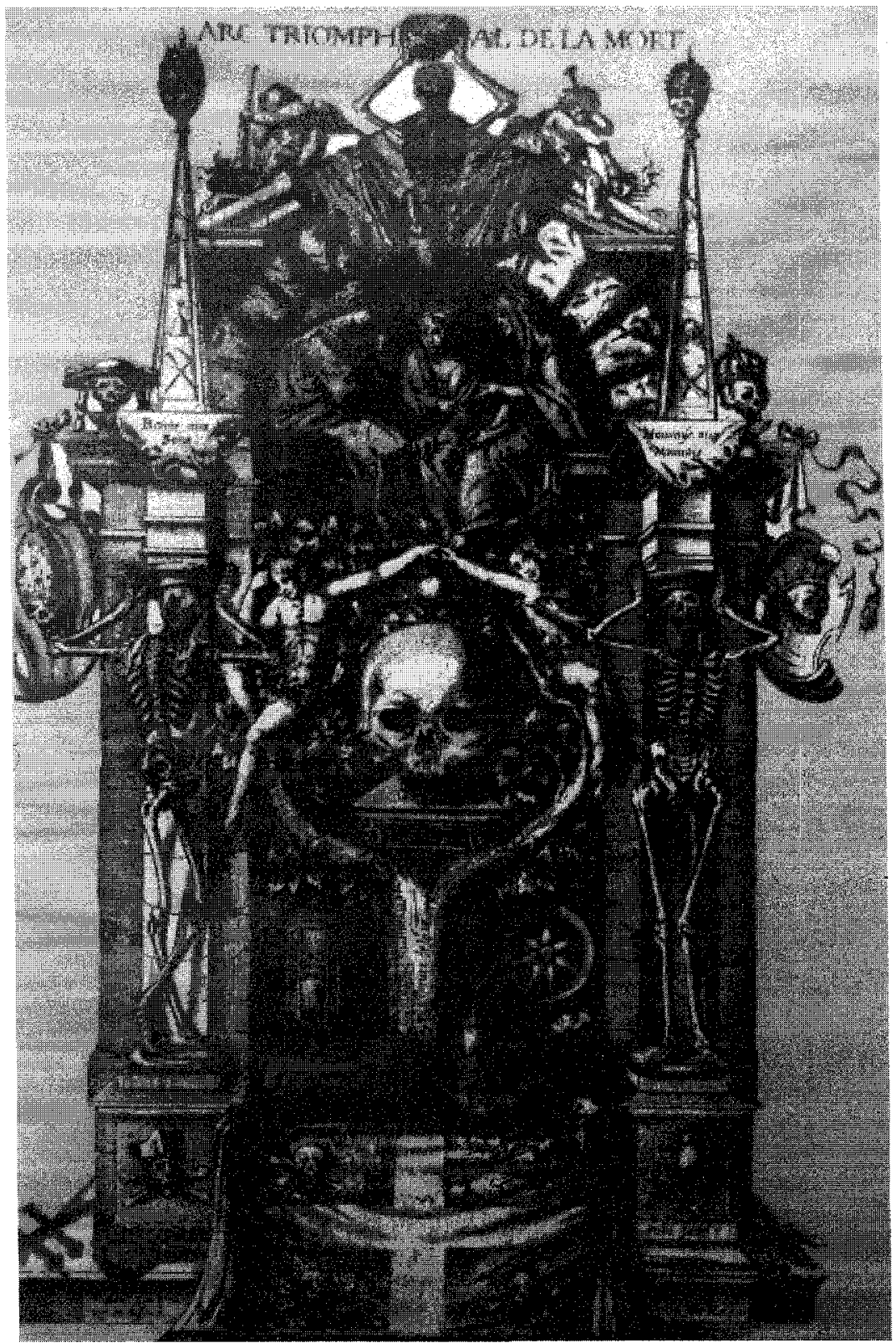

Fig. 7. L'Arc Triomphal de la Mort. 
especialmente en su divulgación realizada por el vallisoletano Luis de la Puente ${ }^{13}$, dedican una parte muy importante a la meditación de nuestras postrimerías. Durante los siglos XVI y XVII los Jesuitas no cesaron de interpretar el libro de su fundador y de abundar en esta meditación. En 1639 celebran en Roma una misa por el eterno descanso de sus benefactores cuyos detalles nos parecen dignos de mención. Se levantó un alto catafalco con todos los adornos que había sido dibujado por el pintor Andrea Sacchi pero cuya disposición se hizo bajo las directrices de los Jesuitas: Mostraba la Muerte apareciendo sobre la tierra al mismo tiempo que el pecado: un esqueleto se apoderaba de Adán y de Eva en el momento en que acababan de coger el fruto prohibido. Sobre un fondo negro destacaban cuatro esqueletos que por encima de su cabeza levantaban cuatro símbolos de poder: una tiara, una corona, un trofeo de armas y un cuerno de la abundancia lleno de oro. Otros esqueletos portaban antorchas mostrando que la vida no se juzga sino a la luz de la muerte. En lo alto del catafalco también se veía la estatua de la inmortalidad, y, en la parte inferior al Papa San Gregorio, es decir, la iglesia, liberando las almas con sus oraciones ${ }^{14}$.

El programa no puede ser más claro: el cristiano ha de mirar directamente a la muerte, que sutilmente se identifica con el pecado - herencia de una de las máximas Trentinas- y también con los primeros Padres, y con la muerte en Cristo. Pero nada debe temer el buen cristiano: mors boris bona. La muerte triunfa sobre todos los poderes, y la Iglesia intercediendo con sus oraciones libera las almas de los pecadores, opone su resistencia ante la muerte, y la gloria eterna, en fin, corona la batalla.

Lo que sorprende es el obsesivo empeño en el pensamiento de la muerte, y su visión desde el punto de vista más doloroso para el hombre, la cruda y aterradora incertidumbre ante la contemplación de las calaveras, los restos de la vida, que resulta tan frecuente después de Trento y se manifiesta tan distante de la vitam non mortem recogita que se inscribe en algún sepulcro renacentista ${ }^{15}$. Cuán distintos son los aterradores sepulcros contrarreformistas, con sus calaveras y esqueletos, de los serenos y laudatorios sepulcros de los humanistas del siglo anterior.

Tras el concilio de Trento, la presencia de calaveras no sólo en sepulcros y ceremonias fúnebres, sino también en múltiples manifestaciones

\footnotetext{
Puente, Luis de la. 1624

Descripción tomada de Mâle, Emile.1985, que indica que se encuentra en la Biblioteca del Vaticano. Barberini. St. V.VII, 112. págs. 326-345.

is El hijo de Peter Vischer de Nuremberg escribió esta frase en uno de los medallones del sepulcro de su padre según Mâle, Emile. 1985, págs. 335.
} 
artísticas, es incesante. Se repiten las imágenes de santos con este atributo, y se les presenta, en un portentoso juego anacrónico, actuando como si estuvieran en unos ejercicios espirituales. De este modo, encontramos a San Francisco, el poeta del Cántico al sol, convertido en un asceta obsesionado por la muerte, a la Magdalena, la poética figura del amor divino, con una calavera entre las manos, a San Jerónimo, el intelectual traductor de la Vulgata, en éxtasis místico. Proliferan las imágenes del niño Jesús recostado sobre la calavera, o sobre la cruz. En definitiva un importante número de obras artísticas insisten en el contraste vanidad (vida) y muerte pretendiendo provocar la reflexión y el arrepentimiento.

El Capitán Alonso de Contreras enumera los trebejos que compra cuando decide hacerse ermitaño en el Moncayo para terminar santamente su vida, y en ellos no faltan ni la calavera ni los emblemas imprescindibles de los cuadros de devoción, y así emprende su camino provisto de «cilicio y disciplinas, sayal de estameña, reloj de sol, calavera, muchos libros penitenciales, semillas y una azada para cultivar la tierra» ${ }^{16}$.

La calavera, cual macabro recordatorio acompaña a los retratos, preside los estudios anatómicos, está impresa en grabados de devoción y aparece en los cuadros de bodegones y floreros llamados vanitates. Definitivamente, se convierte en un instrumento de piedad y en motivo ineludible de pintores, grabadores y escultores así como de literatos y poetas. A su vez, el esqueleto substituye al transido; la llamada por Calderón «muerte seca» deja de ser el doble del vivo para cobrar una personalidad propia, tomando para sí los atributos de Chronos y las armas de Cupido ${ }^{17}$.

Fomentan la fascinación por la muerte no solo las guerras continuas continuas y las hambrunas de la época, sino muy especialmente la crisis religiosa y la reacción de la Iglesia Católica, ante el riesgo de perder su hegemonía que la impele a insistir en su papel de intercesora ante el más allá. Las calaveras y esqueletos son los protagonistas innegable de estas obras, pero junto a ellas hay otros elementos que funcionan en realidad como trasuntos del lenguaje literario propio y característico de este momento. Este nuevo lenguaje insiste en el contraste entre la vanidad del ser humano y la muerte. Encontramos retratos, libros, instrumentos musicales, perfumes, bodegones suntuosos alusivos de los goces sensoriales

\footnotetext{
ib Vida del Capitán Alonso de Contreras, 1965 pág. 99.

${ }_{17}$ Precisamente este es el motivo que aparece en las páginas de los Emblemata de Andrea Alciato, Lugduni 1548. De morte et amore, In formosa praereptam emblemas que reflejan como la muerte y el amor pernoctaron juntos en una venta y a la mañana siguiente tomaron por equivacación las armas cambiadas.
} 
acompañados de otros elementos que recuerdan lo efímero de la existencia: el reloj de arena, la flor que se marchita, las pompas de jabón.

De la existencia anterior de tapices con alusiones a la muerte tenemos noticia por la Testamentaría de Isabel la Católica publicada por Sánchez Cantón ${ }^{18} \mathrm{y}$ estudiada por Antonio Torres del Cerro ${ }^{19}$ que registra entre otros tapices uno que tenía "en medio en lo alto una muerte". Sánchez Cantón edita el documento de Simancas ${ }^{20}$ que resulta especialmente interesante en cuanto refiere la presencia del mundo clásico y aparece como un antecedente del que nos ocupa: Recibistes en la villa de medina del campo a tres días del mes de julio de mil e quinientos e quatro años un paño de ras de figuras que tiene en medio en lo alto la muerte vestida de una vestidura amarilla y morada con una lança en la mano que tiene la punta della puesta en un braço de un labrador e debaxo de sus piés están dos mujeres e un ombre que tiene la muerte tendida la pierna sobre las cabeças dellos e una de las mujeres tiene un rotulo que dize lachesys tray e debaxo esta una mujer vestida de azul con un tocado de pedrería con una Rueca con amas manos e un rotulo en ella que dize Cloto colindo avilad y en la otra part esta una Señora hilando y alos pies della una mujer echada que tiene un rotulo que dize Castitas que tiene de largo quatro varas e de cayda otras quatro varas que se compro de Matis de Guirla.

En mi opinión, pese a haber desaparecido y no poder por tanto corroborarlo, las semejanzas con el Speculum son solo aparentes al no haberse desarrollado todavía un lenguaje de símbolos, propio de la Contrarreforma, con su constante alusión a citas bíblicas o clásicas que reflexionan sobre la condición humana apoyadas por imágenes como las siguientes: La vela encendida y que se apaga, las flores que se marchitan, que lo son a Job (14,12): «El hombre nacido de mujer, corto de días y harto de inquietudes, brota como una flor, huye como una sombra sin pararse". El humo alusivo a la fugacidad de la vida y al texto bíblico del libro de Isaías inscrito en el propio tapiz :sicut fumus transierunt dies mei. La pompa de jabón tan frecuente en las vanitates del Norte inspirada por la reflexión de Virgilio: est homo bulla.

En definitiva todo un complejo código que se corresponde con el que había establecido de un modo perfectamente reglado en la literatura emblemática, muy especialmente por Alciato ${ }^{21}$ en sus Emblemata o por Piero

18 SÁNCHEz CANTÓN, 1954, págs. 104-117.

19 ToRRES y DEL CerRo, Antonio, 1974, pág. 223.

20 Contaduría mayor $1^{\mathrm{a}}$ época leg. 186. Libro de cuentas del Camarero Sancho de Paredes año 1505 en adelante.

21 ALC IATO 1548, Editora nacional 1975, Edición de Santiago Sebastián 1987. 
Valeriano en los Hieroglyphica y que, como señala Fernando Rodriguez de la Flor ${ }^{22}$, surge en principio como un juego de ingenio, pero se pone inmediatamente al servicio de la Contrarreforma. Así podemos entender los Emblemas morales de Horozco inspirados en los de Alciato. En el tapiz que nos ocupa, los símbolos están, a menudo, reforzados y explicados, con las leyendas latinas que hacen el papel de mote o lema, igual que en los emblemas, jeroglíficos y empresas cuyo papel es complementar el discurso moral que transmiten las figuras. Así Saavedra Fajardo culminará sus empresas políticas con un emblema presidido por una calavera alada, símbolo de la fugacidad de la vida, y con el lema latino Ludibria mortis que explicita con un terrible soneto cuyo terceto final advierte.

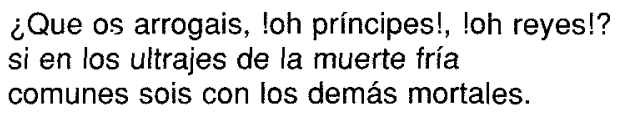

Es este el modo de hacer llegar el mensaje, sin resquicio a la duda, a todo tipo de público. José Manuel Matilla ${ }^{23}$ ha señalado a propósito de ésta complementariedad de los lenguajes, que en las ceremonias celebradas con motivo de las entradas de los monarcas en las ciudades o de las exequias reales, donde eran frecuentes las grandes pinturas y jeroglíficos, existía la costumbre de que los letrados leyesen y tradujeran los textos al gran público, en su inmensa mayoría analfabeto $y$, por supuesto, desconocedor del latín. La palabra y la imagen son, no solo códigos complementarios en determinadas ocasiones, sino también manifestaciones artísticas que corren parejas y sirven a un mismo fin durante el Siglo de Oro, especialmente en España, y ambas tienen un contenido piadoso: Con imágenes santas / la caridad sus actos ejercita / en la deidad que su artificio imita ${ }^{24}$.

Pintura y literatura caminan juntas. Muchos cuadros se basan en textos literarios más complejos, por ejemplo los relativos a las postrimerías humanas. Hay obras como La muerte y el galán de Pedro de Camprobín, basada, al parecer, en El esclavo del demonio de Mira de Amescua, o la más conocida de Antonio de Pereda: El sueño del caballero donde hay quien ve un reflejo de La vida es sueño de Calderón.

En definitiva, existe un interés por los mismos temas: literatura y pintura conviven como códigos complementarios que las hacen compañeras

\footnotetext{
Rodriguez DE LA FLOR, Fernando, 1995, pág. 69.

Matilla, Jose Manuel 1993, págs. 210.

QUEVEDO, 1969 t. 1 versos 147-149.
} 
inseparables. Carducho ${ }^{25}$ señala, refiriéndose a su amigo Lope de Vega, con un lejano eco del horaciano ut pictura poesis: Nota advierte y repara, qué bien pinta, qué bien imita con cuánto afecto y fuerza mueve su pintura las almas de los que le oyen. No es extraño que encontremos en las pinturas, grabados y también en tapices de la época este uso suplementario de las artes, heredero de la tradición clásica y medieval, pero que se manifiesta como creador de un nuevo sistema de símbolos.

Por último, la franja frontal del tapiz ofrece la leyenda Vita brevis hominum, variis obnoxia curis/ Mane viret fax sed vespere nocte cadit ${ }^{26}$ flanqueada por una escena que se reproduce simétricamente y representa la desigual lucha entre el amor y la muerte. El magnífico y minucioso estudio previo a la restauración realizado por Ana Schoebell y Luis Mariano García (fig. 8) indica que sólo el motivo de la lucha entre la Parca, armada con alfange y escudo, y Adonis, con una lanza, que se encuentran en el lado izquierdo, son obra originaria, ya que el resto pertenece a una restauración realizada mediante injerto seguramente a mediados del siglo pasado, que muy probablemente utiliza como modelo el motivo original, aunque sea imposible asegurar que el restaurador no se dejase llevar por su imaginación. El amor y la muerte, tema eterno de la literatura y de las artes, encuentran en el tapiz un desconsolador y trágico epitafio. Los símbolos tan reproducidos en los frisos de Saint Maclou de Rouen, el pico y la pala, ejerciendo de tibias cruzadas, en esta obra aparecen también bajo la medieval inscripción del Memento mori.

La muerte y su triunfo ha sido motivo de reflexión a lo largo de toda la historia en todas las culturas. Hemos visto en el Speculum humanae vitae una consideración conforme a la idea contrarreformista de la existencia, pero también en la Europa reformista abundan las meditaciones sobre la vanidad de la existencia. Iconoclasta y abanderada del poder de la palabra y de la Biblia, la Reforma propicia el desarrollo de un género pictórico, pero que emplea un lenguaje literario muy complejo: las vanitates. Se trata de reflexiones más intelectualizadas, menos sensitivas que las empleadas por la Contrarreforma. El nombre Vanitas se toma de la primera frase del libro del Eclesiastes: Vanitas vanitatum et omnia vanitas. Son toda una serie de naturalezas muertas, retratos, paisajes con ruinas, que cogen alegóricamente en sus representaciones la pregunta ubi sunt ${ }^{27}$ planteada en Isaías $(33,18)$ y repetida en la carta de San Pablo a los Corintios $(1,20)$.

CARDUCHO, Vicente 1979, pág. 212.

LOPEZ REDONDO 1994, pág. 199.

Bia:OSTOCK1, Jan 1972, págs. 146-157. 
En torno al tapiz intitulado Speculum humanae vitae que fue de Doña Emilia...

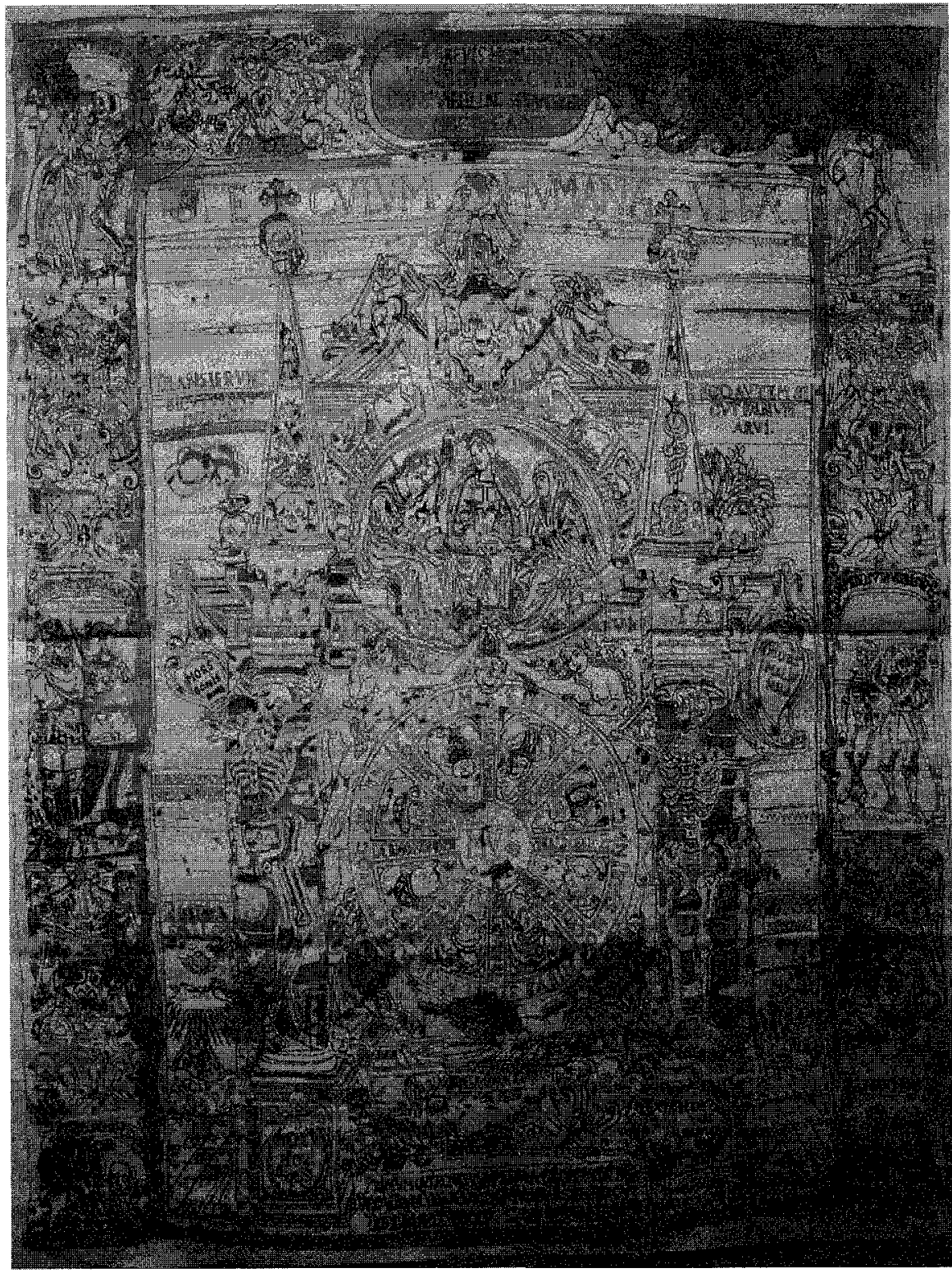

Fig. 8. Dibujo donde se señalan los añadidos del tapiz «Speculum Humanae Vitae». 
Veremos, igual que en el tapiz, símbolos del poder y de la gloria: tiaras, cetros y coronas, libros e instrumentos musicales, máscaras y retratos; alusiones a la fragilidad en las pompas de jabón, en el humo que se desvanece; a la fugacidad del tiempo, en clepsidras y flores que se marchitan y velas que se apagan. Todo ello en extrañas combinaciones formando naturalezas muertas ${ }^{28}$ con su correspondiente moraleja que con frecuencia gozan de la presencia de las calaveras laureadas. Son obras de difícil comprensión, a simple vista semejantes a un cúmulo de objetos, pero que no son meras metonimias fortuitamente dispuestas sino composiciones complejas y poéticas, estampas que transmiten las diversas sensibilidades de los lenguajes de la dividida Europa, hermosas y sutiles en el norte, sensuales y directas en el sur.

Pero la muerte no es solo objeto de reflexión, también es acontecimiento terreno. Cuando la muerte es la de un personaje importante, en especial la de un monarca, tienen lugar una serie de actos, de ceremonias no sólo litúrgicas, sino fundamentalmente civiles, tendentes a exaltar la monarquía ante sus súbditos. Tenemos noticia de estas ceremonias y exequias, gracias a las numerosas relaciones de enfermedades mortales y honras funerales llegadas hasta nosotros, que describen, a menudo con grabados y dibujos, la compleja organización de estos actos de carácter efímero que transforman y convierten la ciudad en la que se realizan en un tremendo escenario laudatorio donde transcurren cortejos fúnebres y se levantan túmulos y catafalcos. En estas relaciones de honras, estudiadas por Victoria Soto ${ }^{29}$ se plasma la idea contrarreformista de la vida y se transfieren al monarca los valores habitualmente atribuidos a la Iglesia.

Por otro lado, este es un tiempo de gran mortandad. No olvidemos que Europa se encuentra en el periodo llamado de guerra de religiones. Los convulsos movimientos de intolerancia siembran la ruina, la muerte y la destrucción. La vida se desenvuelve entre las muertes naturales, las violentas, las ocasionadas por la justicia y los autos de fe, en un tremendo paisaje de convivencia con la muerte ${ }^{30}$. Surgen las cofradías que, como la fundada por Mañara en el Hospital de la Caridad de Sevilla, tienen la misión de enterrar a los ahorcados. Las fiestas de ánimas o las traslaciones de reliquias, son también aconiecimientos seguidos por las multitudes, la muerte es una constante de la vida cotidiana en este periodo tal vez como en ningún otro. Por ello tiene interés estudiar su representación pues ayuda a comprender la mentalidad de la época.

28 Chastel, André 1990. págs, 46-73.

29 SOTO CABA, Victoria 1992.

30. García Fernandez, Máximo. 1996 
Sobre el uso originario de este interesante tapiz, sólo tenemos intuiciones, que nos permiten aventurar que se trata de algo más que una vanitas, es decir de un acicate a reflexionar sobre la muerte, que emplea un lenguaje simbólico basado en referencias literarias tomadas de la Biblia y de la literatura clásica. Es más que una alegoría, porque posiblemente ha sido también un elemento de un decorado fúnebre, tal vez en un convento, tal vez en una familia de la aristocracia. Tampoco cabe descartar que una pequeña parroquia como la de Torre de Esteban Hambrán ${ }^{31}$ tuviera una activa cofradía de ánimas que perpetuase a un nivel popular la tradición de los decorados y arquitecturas efímeras para las exequias reales.

En lo que se refiere, sin embargo a su reciente historia tenemos el interesante testimonio oral del actual poseedor del título nobiliario de Conde de Esteban Collantes que nos ha referido como llegó el tapiz a la familia, y en concreto a manos de Doña Maria Esteban Collantes y Sandoval, que lo donó al Museo de Bellas Artes de la Coruña en 1969. Procede de la herencia de Don Jaime de Quiroga lo que significa que en su momento obró en poder de la Condesa Doña Emilia Pardo Bazán, su madre. Recuerda sobre la tapiz, según nos dice, su terrorífica presencia en el domicilio de Madrid de Doña Emilia, y también que le refirieron que antiguamente su familia tenía el privilegio de velar sus difuntos en sagrado, lo que se realizaba colgando en la correspondiente capilla el tapiz Speculum humanae vitae. La exposición y velatorio del cadáver escenificaba, por decirlo así, el argumento de la colgadura. Esta interesante información nos hace revivir en tono menor el ritual de las grandes exequias de la monarquía, en su manera de transformar un espacio cotidiano, creando el ambiente y el decorado adecuado para la celebración de un rito.

Está comprobado gracias a la amabilidad del Conde de Collantes que nuestro tapiz formó parte del ajuar de Doña Emilia Pardo Bazán, la insigne novelista, pero ignoramos como llegó a su poder. Hemos intentado averiguar algún dato al respecto, examinando documentos que pudieran aportar alguna luz en el museo coruñés que lleva su nombre, sin obtener ningún resultado positivo. Por otro lado, tampoco su obra narrativa aporta datos al respecto, pero de cualquier modo es interesante conocer el hecho de que le perteneció en su día, y el testimonio de esta práctica ritual.

Este tapiz, interesante obra, muestra del pensamiento contrarreformista pese a mostrar en las sonrisas sardónicas de sus esqueletos y calaveras la esperanza de la resurrección que promulga la Iglesia Católica, no deja de conmovernos como los hermosos versos de Quevedo:

31 Cruz Valdovinos. 1980. 
Ya no es ayer, Mañana no ha llegado;

Hoy pasa, y es y fue con movimiento

Que a la muerte me lleva despeñado ${ }^{32}$.

\section{SELECCIÓN BIBLIOGRÁFICA}

AlCIATO, Andrea, 1548: Emblemata, Lugduni, 1548; Editora Nacional, 1975, con prólogo de Manuel MONTERo VALLEJo; Edición de Santiago Sebastián, Cátedra 1987.

ARIĖs, Philippe, 1983: El hombre ante la muerte, Madrid 1983.

BARTSCH, Adam, 1802-1821: Le peintre graveur, Viena, Deyen et Mechetti 1803-1821.

BARTSCH the illustrated 1979: New York 1979.

BialostockI, Jan, 1972: Estilo e iconografía Barcelona 1972.

BRYANS, 1816: Bryans dictionary of Painters and Engravers Illustrated, London 1816.

BUNDETO, Carlos, 1700: El espejo de la muerte, en que se notan los medios de prepararse para bien morir (...) Amberes, 1700.

CARDUCHO, Vicente, 1979: Diálogos de la pintura. Edición de francisco calvo Serraller, Madrid 1979.

Coste Messelière, Marie Genevieve de LA, 1959: «Pompes funèbres» en L'oeil no 59.

Cruz Valdovinos, 1980: «Un catafalco rococó en la Torre de Esteban Hambrán» en Goya nº 155 de 1980.

CHASTEL, André, 1990: "Glorieuses vanités" en Vanités dans le peinture au XVII sécle meditation sur la richesse, le denuement et la redemption, Caén, Musée des Beaux Arts 1990.

FERnÁNdeZ BAyton, Gloria, 1985: Inventarios reales. Testamentaría de Carios II. Madrid, Museo del Prado 1985.

FoRTUNIUS, Fortuna, 1588: [a wood-engraving in chiaro-scuro,emblematical of Death «J.F.F. Inveni 1588" with a collection of engravings various artists representing sepulchra monuments, funeral ceremonies, etc. $1518-1630$ fol.

García Fernandez, Máximo, 1996: Los castellanos y la muerte. Junta de Castilla y León 1996.

LE BLAivic, M.Ch., 1854: Manuel de l'amateur d'estampes, París 1854.

LóPEz REDONDO, Amparo 1994: «Speculum humanae vitae: un tapiz existente en el museo de Bellas Artes de La Coruña" Abrente no 26.

MÂLE, Emile, 1985: El Barroco: arte religoso del siglo XVII, Barcelona, Rauter, 1985.

MATHLA, José Manuel, 1993: «La poesía efímera al servicio de la monarquía». Catálogo de la exposición Verso e Imagen del Barroco al Siglo de las luces. Comunidad de Madrid 1993.

PUENTE, LUIS DE LA, 1624: Meditaciones Espirituales, Valladolid 1624.

QUEVEDO, Francisco de, 1969: Obras completas edición de José Manuel Blecua, Castalia 1969.

Rodriguez DE LA FLOR, Fernando, 1995: Emblemas. Lecturas de la imagen simbólica; Madrid, Alianza 1995.

SÁNCHEZ CANTÓN, 1954: Testamentaría de Isabel la Católica, Madrid, Consejo Superior de Investigaciones Científias 1954.

Soto CABA, Victoria, 1990: Los catafalcos reales del barroco español. Madrid, U.N.E.D., Aula Abierta, 1992.

TENENT1, Alberto, 1957: / senso della morte e l'amore della vita nel rinascimento, Torino, Einaudi, 1957.

TORRES DEL Cerro, Antonio, 1974: Testamentaría de Isabel la Católica Barcelona 1974.

Vida del Capitan Alonso Contreras, 1965.: Vida del Capitan Alonso de Contreras, ed. y prólogo Criado del Val, Madrid, Taurus, 1965

32 Quevedo, Francisco de, 1969, pág. 150. 